\title{
Burocratas de médio escalão: novos olhares sobre velhos atores da produção de políticas públicas
}

\author{
Gabriela Spanghero Lotta \\ Universidade Federal do $A B C$ (UFABC) \\ Roberto Rocha Coelho Pires
}

Instituto de Pesquisa Econômica Aplicada (Ipea)

Vanessa Elias Oliveira

Universidade Federal do $A B C$ (UFABC)

O artigo tem como objetivo apresentar os resultados de uma revisão da literatura nacional e internacional sobre burocratas de médio escalão (BMEs). A sistematização da literatura se orientou a partir de uma perspectiva de políticas públicas, voltada para a compreensão da existência e atuação desses atores e das suas influências sobre os processos de produção de políticas públicas e ações governamentais. Três dimensões da atuação da burocracia de médio escalão foram analisadas: seus papéis, funções e "lugares"; as perspectivas analíticas a partir das quais são observados (estrutural, individual e relacional); e, por fim, a sua atuação nas políticas públicas setoriais. Dois aspectos merecem destaque a partir da revisão bibliográfica empreendida. Em primeiro lugar, o fato de que os BMEs merecem maior atenção nas análises dos processos de produção de políticas públicas. Somado a isso, explicitam-se as ausências existentes na literatura nacional no que tange à relevância e centralidade desse ator.

Palavras-chave: burocracia, administração pública, políticas públicas, agente público

Artigo recebido em junho de 2014. Versão final em outubro de 2014. 
Burócratas de medio escalafón: nuevas miradas sobre viejos actores de la producción de políticas públicas

El artículo tiene como objetivo presentar los resultados de una revisión de la literatura nacional e internacional acerca de los burócratas de nivel medio (BMES). La sistematización de la literatura se guió desde una perspectiva de las políticas públicas, se centró en la comprensión de la existencia y las actividades de estos actores y sus influencias en los procesos de producción de las políticas públicas y las acciones gubernamentales. Se analizaron tres dimensiones del desempeño de la burocracia de nivel medio: sus roles, funciones y "lugares"; perspectivas analíticas de las que se observan (estructural, relacional e individual); y, por último, su rendimiento en las políticas del sector público. Dos aspectos deben destacarse de la revisión bibliográfica realizada. En primer lugar, el hecho de que los BME merecen más atención en el análisis de los procesos de producción de las políticas públicas. Sumado a esto, se explicitan las ausencias existentes en la literatura nacional sobre la relevancia y centralidad de este actor.

Palabras clave: burocracia, administración federal brasileña, políticas públicas, funcionario público

\section{Mid-Level Bureaucrats: new perspectives on traditional actors in policy production}

The article aims at presenting the findings from a literature review (considering both domestic and international productions) on mid-level bureaucrats (MLBs). The organization and analysis of the material was guided by a public policy perspective, focused on understanding the existence and behavior of these actors and their influence on governmental action. We analyzed three distinct dimensions about MLB influence on policy: a) their roles, functions, and "places"; b) the analytical perspectives mobilized to make sense of them (structural, individual, and relational); and c) MLB's behavior in specific policy areas. Two aspects emerge from the literature review. First, MLBs deserve greater attention in our analysis of the policymaking and implementation processes. Second, this type of analysis is largely absent in the Brazilian scholarly production.

Keywords: bureaucracy, public administration, public policy, civil servant 


\section{Introdução ${ }^{1}$}

O presente artigo tem como objetivo apresentar os resultados de uma revisão da literatura nacional e internacional sobre burocratas de médio escalão (BMEs). Trata-se dos atores que desempenham função de gestão e direção intermediária (como gerentes, diretores, coordenadores ou supervisores) em burocracias públicas e privadas. A sistematização da literatura se orientou a partir de uma perspectiva de políticas públicas - isto é, voltada para a compreensão da existência e atuação desses atores e das suas influências sobre os processos de produção de políticas públicas e ações governamentais.

Os estudos de políticas públicas têm ganhado espaço apenas recentemente e, apesar do crescimento das pesquisas nas últimas décadas no Brasil, o campo das políticas públicas ainda sofre, em certa medida, da grande fragmentação organizacional e temática (FARIA, 2003). Além disso, há também lacunas quando observamos o recente espaço que a literatura de políticas públicas tem dado para ampliar as formas de análise das ações do Estado, incluindo novos atores e novos modelos analíticos. Algumas pesquisas têm demonstrado a incapacidade que os modelos tradicionais de interpretação dos mecanismos de intermediação de interesses, como pluralismo, marxismo e teoria das elites, têm de dar conta da diversificação e complexificação dos processos, marcados por interações não hierárquicas, "por um baixo grau de formalização no intercâmbio de recursos e informações, bem como pela participação de novos atores." (FARIA, 2003).

$\mathrm{Na}$ tentativa de elucidar características do processo de produção das políticas, entraram na agenda de pesquisas expressões como issue networks, policy communities, além de questões como diversificação dos atores envolvidos, padrão de relacionamento entre áreas etc. No entanto, essa nova agenda de pesquisa parece ainda estar centrada nas análises, sobretudo empíricas, acerca dos processos de tomada de decisão, com restrita atenção dada aos processos de implementação.

Quando analisamos a literatura sobre as políticas públicas, percebemos a menor relevância dada à fase da implementação, visto a quantidade ainda relativamente limitada de trabalhos sobre o assunto desde o memorável trabalho de Lipsky sobre a Street-Level Bureaucracy (1980), especialmente quando analisada a produção nacional sobre o tema. Há, portanto, uma lacuna nos estudos empíricos

\footnotetext{
${ }^{1}$ A realização deste trabalho contou com a valiosa assistência de estagiários e bolsistas de iniciação científica. Registramos nossos agradecimentos a Eveline Ribeiro dos Santos, Cleiton Duarte e Luiz Fernando Biscardi.
} 
brasileiros a respeito dos diversos elementos e fatores que influenciam a fase da implementação, muito embora alguns trabalhos pioneiros busquem trazer o olhar para as policy networks (MARQUES, 2003, CARPIM, 2003), para a importância da aprendizagem e conhecimento (FARIA, 2003) ou para incorporação de valores dos burocratas (Meier e O'Toole, 2007 e LotTA, 2010).

Essa limitação da literatura se dá também em relação ao olhar que tem sido dado ao papel das diferentes burocracias no processo entre formulação e implementação das políticas.

Conforme expôs Oliveira (2009), a maioria das pesquisas desenvolvidas sobre burocracia pública no Brasil centra-se na burocracia de alto escalão, e mais especificamente a burocracia federal, e como essa atua no processo de produção de políticas públicas (GouvêA, 1994; SCHNEIDER, 1994; Loureiro, Abrucio e Rosa, 1998; Loureiro e Abrucio, 1999; Bresser Pereira, 2007; Olivieri, 2007). Outros trabalhos voltam-se, ainda, para a chamada "burocracia de nível de rua" (LIPSKr, 1980), que implementa as políticas desenhadas "centralmente" pelo alto escalão (LotTa, 2010, por exemplo) (Oliveira e Aвrucio, 2011, p.2).

No entanto, poucos são os estudos voltados a compreender a burocracia intermediária que gerencia os burocratas de nível de rua e que fazem o elo entre esses implementadores e os formuladores (Howlett, 2011; Meier, 2009; PIRES, 2011; Oliveira e Abrucio, 2011). Dessa burocracia de médio escalão, fazem parte os gerentes, dirigentes, supervisores e agentes encarregados de operacionalizar as estratégias que o alto escalão da burocracia formula (PIREs, 2010).

Trata-se de um conjunto central de atores nos processos de implementação de políticas públicas, porém pouco considerado nos modelos de análise. Os estudos pioneiros dos anos 1970 tendiam a focar nos processos de tomada de decisão e a assumir a implementação como um processo hierárquico, que vinha de cima para baixo (abordagem top-down). Nessa perspectiva, os burocratas eram claramente subordinados aos tomadores de decisão, pressupondo uma separação entre administradores e políticos e uma tradução automática entre decisão e ação (HıL e HAM, 1993).

Nas décadas seguintes, passou-se a valorizar o olhar para a efetividade e avaliação das políticas, percebendo-se que alguns fatores levavam o processo de implementação a falhas (Pressman e WiLdAvsky, 1984, Gunn, 1978, SAbatier e Mazmanian, 1979). A partir de análise de "baixo para cima", os atores responsáveis pela implementação passaram a ser compreendidos como elementos-chave. Lipsky (1980) demonstrou que os agentes de rua (street-level bureaucrats) são funcionários que trabalham diretamente no contato com os usuários dos serviços públicos 
(policiais, professores, profissionais de saúde etc.), e afetam diretamente o desempenho, a qualidade e o acesso aos bens e serviços providos pelo governo. Assim, a abordagem bottom-up desafiou a visão tradicional centrada em processos hierárquicos e sugeriu que a implementação deveria ser vista como parte contínua e integral do processo político, envolvendo barganha e negociação entre os que querem colocar a política em ação e os de quem as ações dependem.

Tendo em vista essas posições extremas, pouco se preocupou em compreender um conjunto de atores que, "por ocupar uma posição intermediária, se situa em um 'limbo' conceitual entre as abordagens top-down e bottom-up, os burocratas de médio escalão (...) que designam uma posição intermediária entre o topo e a base" (PIres, 2011, p.4). Oliveira (2009), Pires (2011) e Oliveira e Abrucio (2011) também destacam que há uma variedade e heterogeneidade de atores que ocupam essa posição intermediária denominada "burocracia de médio escalão". Essa heterogeneidade se dá tanto pelos contextos setoriais e institucionais quanto pelos próprios cargos exercidos por cada um deles. Esse reconhecimento, no entanto, implica a necessidade de esforços comparativos e consistentes para caracterização empírica desses perfis, de forma a construirmos conceitos mais precisos compreendendo suas generalidades e especificidades.

Para além da relevância teórica do objeto, observa-se atualmente, no plano empírico, um processo de expansão dessa burocracia intermediária no Brasil. De 1997 a 2012, ocorreu, no Governo Federal brasileiro, uma forte expansão do número de cargos associados a essa posição intermediária nas hierarquias burocráticas 107\% de aumento no número de cargos de Direção e Assessoramento Superior (DAS) nível 4, e 91\% para o nível 5. Essa expansão observada nos níveis intermediários supera o aumento ocorrido no número de cargos em outros níveis de DAS (1, 2, 3 e 6) e se situa em patamar muito superior à média geral (27\%) de crescimento de DAS. A expansão destacada no segmento de gerência intermediária sugere que a burocracia de médio escalão tem sido alvo de transformações importantes e ganha relevância para a atividade governamental no período recente. ${ }^{2}$

\footnotetext{
2 Na estrutura de cargos comissionados do Governo Federal, há sete posições, associadas aos denominados Cargos de Direção e Assessoramento Superior (DAS) e Cargos de Natureza Especial (NE). Há seis níveis de DAS, sendo que o DAS 1 é o menor cargo na estrutura hierárquica e o DAS 6, o maior. Os Cargos de Natureza Especial são superiores ao DAS 6. Num olhar a partir da estrutura, os cargos podem ser vistos como: DAS 1 a 3 correspondem a cargos de baixo escalão; DAS 4 e 5, de médio escalão; DAS 6 e NE, alto escalão.
} 
Assim, esse conjunto de inquietações teóricas e movimentações do fenômeno empírico indicam a necessidade de ampliarmos a nossa compreensão sobre quem são esses atores, o que fazem, como atuam, com quem se relacionam e de que forma influenciam a gestão de políticas públicas. Esse é o sentido da investigação proposta por este artigo, o qual se baseia em extensa e sistemática revisão da literatura sobre o tema em distintas áreas de conhecimento aplicadas à gestão de políticas públicas.

Na seção seguinte, descrevemos a metodologia utilizada para o levantamento bibliográfico e os procedimentos empregados para a sistematização e análise do material. Em seguida, os resultados de tal revisão e a sistematização da literatura são apresentados. Em um primeiro momento, focamos nas definições encontradas para o conceito de "burocratas de médio escalão" e sua operacionalização, assim como na caracterização do contexto, evolução e descrição dos papéis desempenhados por esses atores, além dos dilemas de construção de suas identidades e suas formas de atuação. Em um segundo momento, buscamos sistematizar as três principais abordagens ou perspectivas (estrutural, individual e relacional) para a análise da atuação e influência dos burocratas de médio escalão sobre os processos de produção de políticas públicas, com o foco em alguns estudos setoriais. Por fim, concluímos com uma síntese dos principais elementos levantados a partir da revisão bibliográfica, os quais, simultaneamente, sustentam a importância do foco nesse ator específico e contribuem para o preenchimento de lacunas no debate sobre políticas públicas, apontando uma agenda de pesquisa futura sobre burocratas de médio escalão.

\section{Metodologia}

Para analisar o que já foi publicado em periódicos sobre o tema, buscamos em bases digitais acadêmicas todas as publicações nacionais e internacionais conceituadas como Qualis A ou B dos campos de ciência política, ciências sociais, administração pública, ciências sociais aplicadas e interdisciplinar. Selecionamos as publicações com mais afinidade à análise de políticas públicas e definimos um conjunto de 64 periódicos a serem consultados. Em cada um deles, foi realizada uma busca, utilizando como palavras-chave "burocracia", "gerente", "burocrata", "gestor" ou "dirigente", sempre combinadas com "organizações públicas", "administração pública", "Estado" ou "políticas públicas" e suas respectivas traduções para a busca internacional.

De todos os periódicos analisados, foram extraídos 85 artigos, novamente filtrados, em função dos resumos, pela aderência ao tema - o que resultou numa seleção de 6 artigos nacionais e 28 artigos internacionais. 
Além disso, realizou-se uma busca no portal Capes por meio de três palavraschave: "mid-level bureaucrats", "middle level bureaucracy" e "bureaucratic behavior". Para cada um dos termos, foram analisadas as 100 primeiras ocorrências classificadas automaticamente por ordem de relevância, resultando em mais 44 artigos internacionais.

A esse conjunto, foram somados artigos internacionais da literatura da administração e da ciência política previamente selecionados por especialistas do tema, chegando a um total de 83 artigos $^{3}$. Todos os artigos foram lidos e sistematizados, tendo como base a identificação dos seguintes elementos em cada artigo: objetivo; objeto central; metodologia; variável dependente e variável explicativa; principais conclusões sobre os BMEs.

A partir desses procedimentos, a revisão da literatura buscou identificar como a literatura trata os BMEs. Por um lado, percebeu-se que abordagens disciplinares distintas tendem a enfocar diferentes aspectos no estudo desses burocratas. Enquanto estudos da ciência política tendem a atribuir maior relevância à participação dos BMEs nos processos decisórios internos às burocracias (conflitos, coalizões etc.), à relação deles com atores externos (como políticos, partidos e cidadãos) e aos dilemas entre autonomia e controle das burocracias, estudos na área de administração e psicologia tendem a ressaltar temas como motivação, liderança, aprendizado, sentimentos em relação ao trabalho, modelos de recrutamento e outros temas associados à gestão de recursos humanos, além de enfoques voltados às estruturas e processos administrativos. Temas associados às estruturas organizacionais, identidades, papel das profissões, cultura organizacional ou ocupacional são também frequentemente abordados por sociólogos.

Todavia, apesar dessa variedade de abordagens, a sistematização da literatura se pautou por preocupações típicas das reflexões sobre a produção e análise de políticas públicas, dado que, como previamente apontado, trata-se de um campo de conhecimento no qual o foco nos BMEs tem sido pouco explorado. Assim, a interpretação dos conteúdos extraídos da bibliografia levantada foi orientada no sentido da extração de conceitos, categorias e abordagens que permitam ampliar a compreensão sobre quem são os BMEs, o que fazem, como atuam e como influenciam o desenho e a implementação de políticas públicas.

\footnotetext{
${ }^{3}$ Não é possível analisar a separação dos artigos entre as áreas de conhecimento (ciência política, administração etc.), já que a mesma revista pode estar presente em mais de uma área de conhecimento ao mesmo tempo.
} 


\section{Os burocratas de médio escalão na literatura sobre gestão e políticas públicas}

Esta seção apresenta resultados da sistematização da literatura pesquisada. Primeiramente, focamos contexto, evolução e descrição dos papéis desempenhados por burocratas de médio escalão, além dos dilemas de construção de suas identidades e suas formas de atuação. Na segunda subseção, apresentamos três perspectivas analíticas para a compreensão da atuação dos BMEs na produção de políticas públicas. Por fim, apresentamos algumas análises setoriais.

\section{O burocrata de médio escalão: papéis, funções e "lugares"}

Nesta primeira subseção, será apresentado um retrato mais geral do que a literatura já tem concluído a respeito dos BMEs. Ela está organizada em três partes que apresentam, cada uma, elementos específicos que essa literatura busca sistematizar: a) definições e indefinições da literatura sobre os BMEs; b) papéis que a literatura identifica para os BMEs; c) valores e comportamento dos BMEs.

\section{a) Os BMEs em contexto: definições e indefinições}

Uma primeira conclusão que se pode extrair da literatura diz respeito à ambiguidade e à dificuldade de definir com exatidão o que caracteriza um burocrata de nível médio. Para efeitos de simplificação e operacionalização, a forma mais frequente de se definir um BME ocorre pela identificação daqueles funcionários situados no meio da estrutura hierárquica da organização. Isto é, pela eliminação dos cargos e funções associados aos extratos superiores e inferiores, ou pelo foco nos cargos de gerência intermediária na estrutura administrativa (como diretores, coordenadores, gerentes, supervisores etc.).

Nos estudos da administração de organizações privadas, os funcionários de médio escalão têm sido definidos como ocupantes de cargos de gerência situados entre o grupo de dirigentes estratégicos do topo (por exemplo, os CEOs) e a primeira linha de supervisão (chefes de divisão, coordenadores de projetos etc.), acima dos empregados encarregados diretamente com a produção (VIE, 2010). Em estudos voltados para burocracias do setor público, a definição e operacionalização do conceito de BME mais usual tem focado nas categorias intermediárias das estruturas de cargos de gerência. Por exemplo, Lewis (1992), ao estudar os middle managers no governo federal norte-americano, delimitou sua análise aos cargos de gerência identificados como GS-13 a 15, sendo que GS-16 a 18 correspondem ao Senior Executive Service e os graus menores que 13 se referem a funções de primeira linha de gerência. No caso do Governo Federal 
brasileiro, esse extrato intermediário corresponderia aos cargos de DAS de nível 4 e 5 (na escala que vai de 1 a 6 ).

No entanto, a literatura reconhece que, apesar de necessárias, essas simplificações, a partir de posições na estrutura administrativa, não refletem a complexidade associada aos níveis intermediários. Na prática e no cotidiano das organizações públicas e privadas, percebe-se que há confusos limites em torno do termo "médio" ou "intermediário" e ambiguidades na definição de quem são ou não são esses burocratas de médio escalão.

Isso se deve ao fato de que as camadas intermediárias de organizações públicas e privadas têm passado por diversas transformações, acarretando instabilidade nos papéis, funções e identidades dos atores que ocupam esses espaços organizacionais (THOMAS; LINSTEAD, 2002). Tais processos têm sido mais intensos no setor privado, mas também se fazem presentes nas burocracias públicas, sobretudo a partir do paradigma da Nova Gestão Pública. Nas últimas décadas, movimentos como de reengenharia, downsizing, desburocratização, gerencialismo têm promovido o enxugamento de camadas hierárquicas que se concretiza, principalmente, em um achatamento das estruturas organizacionais. Novas tecnologias têm permitido o monitoramento e a condução das atividades operacionais na ponta por parte de dirigentes superiores. Além disso, metodologias de trabalho em equipe, estruturas matriciais ou baseadas em projetos, e muitas outras reformas que reduziram estruturas hierárquicas têm como consequência a própria redução dos cargos de nível intermediário - o que significaria a potencial extinção dos BMEs (SOFER, 1974; VIE, 2010).

Por outro lado, a intensidade dessas transformações tem criado também oportunidades para o reposicionamento desses atores, a partir dos discursos do empreendedorismo, da liderança e do engajamento estratégico, no setor privado (THOMAS; LINSTEAD, 2002); ou da expectativa de emergência de new public managers, no setor público (Thiel, Stein; A Alux, 2005). Assim, embora os autores considerem que os processos de reforma do Estado têm trazido mudanças que impactam a atuação, perfil e papel dos BMEs, na literatura voltada ao setor público, não há necessariamente um entendimento de que essas funções estão se reduzindo, mas, sim, se transformando e adquirindo outra importância. Assim, percebe-se a complexidade do debate sobre a burocracia intermediária e as dificuldades de definição e operacionalização do conceito.

\section{b) Os papéis e funções dos BMEs}

Com relação aos papéis e funções desempenhados pelos BMEs, encontramos distinções importantes entre os estudos que focaram burocracias públicas e organizações privadas. 
O estudo de Mintzberg (1973) sobre os papéis desempenhados por gerentes é provavelmente um dos mais influentes no debate sobre o papel dos BMEs no setor privado. Diferentemente dos estudos clássicos na administração, que prescreviam como funções essenciais de gerência o planejamento, coordenação e monitoramento, Mintzberg, a partir de uma metodologia observacional, descreveu essa atividade como altamente fragmentada, variada e baseada em tentativas de curto prazo de lidar com problemas emergentes. Em vez de desempenhar funções típicas de administração, como pensamento analítico e ação, o papel dos gerentes poderia ser definido a partir de três categorias gerais de função: interpessoais, informacionais e decisórias. A dimensão interpessoal sugere que a atividade de gerência envolve capacidade de interação com superiores, subordinados e pares. A dimensão informacional chama atenção para o papel dos gerentes na recepção, sistematização e disseminação de informações relevantes para a organização. Finalmente, a dimensão decisória evoca o caráter empreendedor e negociador dos gerentes, além de suas habilidades de lidar com conflitos e alocar recursos estrategicamente (ChAREANPUNSIRIKUL; Wood, 2002). Um amplo conjunto de estudos mais recentes tem argumentado que, nas últimas décadas, o papel dos gerentes vem migrando gradualmente para maior ênfase em atividades de contato interpessoal, diálogo e liderança do que atividade de gestão de processos rotineiros e controles burocráticos (VIE, 2010).

De fato, os estudos pioneiros na administração voltados para o comportamento dos BMEs já haviam identificado que gerentes dedicavam uma maior proporção de seu tempo de trabalho a conversações, em sua maioria envolvendo seus pares em comunicações laterais, e uma menor parte com seus subordinados imediatos (BURNs, 1954 apud VIE, 2010); ou, ainda, que "gerentes passam a maior parte do seu tempo conversando, na maioria das vezes em interações face a face. Eles parecem não estar sobrecarregados com papeladas ou reuniões formais" (HORNE; LUPTON, 1965 p.32 apud VIE, 2010). Estudos mais contemporâneos, segundo Vie (2010), confirmam a manutenção desses mesmos padrões de comportamento no setor privado.

Nos estudos com foco nas burocracias governamentais, ganham relevância reflexões a partir da dicotomia técnico-política. Nesses casos, por ocuparem posições intermediárias, esses BMEs desempenham um papel técnico-gerencial e outro técnico-político (PIRES, 2011). No primeiro caso, as ações dizem respeito a como esses burocratas traduzem as determinações estratégicas em ações cotidianas nas organizações, construindo padrões de procedimentos e gerenciando os serviços, portanto, os burocratas implementadores (WILSON, 1968; KAUfMAN, 1960; Dalton, 1959; ChetKovitch e Kirp, 2001; Oliveira, 2009). No segundo caso, o papel técnicopolítico diz respeito a como esses atores constroem negociações e barganhas relacionadas aos processos em que estão envolvidos e sua relação com o alto 
escalão. Nessa perspectiva, vale ressaltar que o papel técnico-político e sua relevância dependem diretamente da posição desses burocratas no desenho institucional das políticas e, portanto, na cadeia de atores entre a formulação e a implementação (ROCHA, 2003; BIANCCHI, 2002; SCHNEIDER, 1994).

Numa perspectiva um pouco diferente, parte da literatura considera que há mudanças recentes no Estado que fragilizam a ideia de uma dicotomia técnicopolítica (Howlett, 2011; DemIR; RedDICK, 2012). Essas mudanças também apontam a necessidade de compreender os gestores no processo de produção de políticas públicas (HowletT, 2011). O autor assinala três movimentos em curso que reforçam a importância desses atores:

1) O processo de descentralização promovido nos últimos anos em diversos países transferiu papéis importantes para os gestores situados nos níveis baixos e médios das agências governamentais, que passam a se responsabilizar por decisões centrais das políticas públicas.

2) A emergência de redes de governo colaborativo como nova forma de governança aumentou o escopo de influência desses gestores intermediários no seu exercício de autoridade - que agora não é apenas top-down, mas também bottom-up.

3) A orientação voltada aos usuários dos serviços, componente importante do movimento do New Public Management, também fortaleceu a voz e o nível das agências que entregam serviços e os gestores que as dirigem, de forma que os gestores agora têm grande potencial de exercer influência no processo político em termos organizacionais, políticos e técnicos (Howlett, 2011; Wu et al., 2010).

Analisando os estudos recentes sobre a burocracia, Howlett (2011) afirma que muitos têm levado a um questionamento da dicotomia técnico-política e seu entendimento das políticas públicas. Para o autor, falta ainda à literatura uma caracterização mais profunda a respeito dos papéis atuados por gestores intermediários, o que Meier (2009) chamou de "missing variable" nos estudos de políticas públicas.

Alguns estudos têm se dedicado a compreender quando e sob que condições os BMEs conseguem influenciar as decisões estratégicas das organizações. Kelly e Gennard (2007), em estudo qualitativo sobre diretores de empresas privadas, identificaram que aqueles que conseguem combinar sua inserção técnicoespecializada na organização com habilidades genéricas de gestão apresentam maior capacidade de influência, pois asseguram à liderança estratégica da organização preocupações não apenas técnicas como também orientadas para o negócio. 
Currie e Procter (2005), a partir de análises focadas em hospitais públicos, indicam que os BMEs com frequência influenciam as estratégias gerais de suas organizações. Segundo os autores, os BMEs frequentemente "vendem" ideias aos executivos de suas organizações e, muitas vezes, se tornam os responsáveis pela elaboração (e modificação) do conteúdo detalhado das estratégias definidas acima. O grau de influência desses atores intermediários pode depender do seu posicionamento na estrutura organizacional, do nível de conflito com os profissionais responsáveis pelas operações cotidianas e da sua sensibilidade para compreender o contexto estratégico no qual se insere a organização (KURATKo et al., 2005).

\section{c) Comportamento, valores e motivação}

Outro enfoque abordado na literatura atém-se ao comportamento dessa burocracia em contextos organizacionais, especialmente num contexto de reforma e mudanças institucionais. A maioria dos textos analisados busca compreender como os valores desses burocratas têm-se alterado (ou não), considerando os processos de reforma do Estado em curso, norteados por novos valores do New Public Management.

Um dos principais instrumentos aplicados e analisados é o PSM (Public Service Motivation) e suas variações, como PSV (Public Service Values), a partir do qual a literatura busca metrificar valores em curso em determinadas organizações e como eles se alteram (Gains; John, 2010; Witesman; Walters, 2013; Meyer et al., 2013; Jacobson, 2011).

Ainda na linha de compreensão dos valores e motivações dos servidores, há estudos que se voltam a comparar gestores intermediários de organizações públicas com aqueles da iniciativa privada e do terceiro setor (LeE; WiLKINS, 2011; Chen; Bozeman, 2014; Oliveira et al., 2010). Para esses autores, os gestores que atuam no setor público têm preferências, motivações e valores bastante distintos, que podem levar a resultados diferentes das demais organizações. Essa diferença de valores está relacionada tanto ao que os gestores pensam a respeito de salário e benefícios, como a seus compromissos com o interesse público e sentimento de responsabilidade (LeE; WILKINS, 2011), ou, ainda, está relacionada a "tipos de burocratas" que se caracterizam por suas preferências e pela alocação de tempo de trabalho em diferentes funções (GAINs; JoHn, 2010). Por outro lado, gestores públicos tendem a ter uma percepção de que suas habilidades são menos aproveitadas e seu trabalho é menos estimulante, o que pode afetar a qualidade do serviço que desempenham (Chen; Bozeman, 2014). 


\begin{tabular}{|c|c|c|}
\hline & “Para cima” & “Para baixo" \\
\hline Divergente & Priorizando alternativas & Facilitando adaptações \\
\hline Integradora & Sintetizando informações & $\begin{array}{l}\text { Implementando estratégias } \\
\text { deliberadas }\end{array}$ \\
\hline
\end{tabular}

Fonte: Floyd; Wooldridge, 1992 apud Currie; Procter, 2003.

Figura 1: Tipologia da influência da burocracia de médio escalão

Outra questão analisada pela literatura a respeito dos burocratas de médio escalão é das competências relacionadas às suas atividades. Para a literatura, as distintas competências se relacionam tanto às características pessoais quanto àquelas envolvidas na capacidade de interações interpessoais, o que envolve a influência exercida pelos middle managers "para cima", na relação com o alto escalão (executive managers), e "para baixo", com a burocracia de nível de rua, como proposto por Floyd e Wooldridge (1992). Dessa interação "para cima" e "para baixo" (dimensão "direção da influência"), há ainda duas possibilidades de relação com esses estratos da burocracia, que são relacionadas com o posicionamento da BME diante das estratégias para a organização e/ou políticas públicas formuladas. Esquematicamente, a compreensão dessas dimensões e atuação da BME fica mais clara (Figura 1).

Para Floyd e Wooldridge (1992), a BME participa não apenas do "fazer", mas do "pensar" as estratégias de atuação da organização e/ou desenho da política pública. Assim, quando divergem do alto escalão, priorizam alternativas que individualmente consideram as mais apropriadas e/ou importantes, ao passo que, quando estão alinhados, atuando de maneira integradora, são capazes de sintetizar todas as diretrizes da política, transformando-as em ação institucional. No que diz respeito à sua relação com a burocracia de nível de rua, permitem adaptações locais justamente quando discordam da posição defendida pela política; ou implementam estratégias determinadas por ela no que diz respeito à atuação desejada da burocracia implementadora.

Portanto, a atuação da BME é influenciada tanto pelos objetivos estratégicos determinados para a sua organização, traduzindo-os em planos de ação, quanto pelos seus objetivos individuais (CURRIE; Procter, 2003, p. 1327).

Bacon et al. (1996) assinalam outras duas diferenças fundamentais entre as burocracias públicas e privadas. Primeiro, a avaliação dos serviços prestados no setor 
Quadro 1: Características dos gestores nas iniciativas pública e privada

\begin{tabular}{|c|c|}
\hline Gestores no setor público & Gestores no setor privado \\
\hline $\begin{array}{l}\text { Foco em compromisso com interesse } \\
\text { público e sentimento de responsa- } \\
\text { bilidade (LEe; WiLKINS, 2011). }\end{array}$ & $\begin{array}{l}\text { Foco em salário e benefícios (LEE; WILKINS, } \\
\text { 2011). }\end{array}$ \\
\hline $\begin{array}{l}\text { Percepção de que habilidades são menos } \\
\text { aproveitadas em seu trabalho (CHEN; } \\
\text { BOZEMAN, 2014). }\end{array}$ & $\begin{array}{l}\text { Percepção de que habilidades são bem } \\
\text { aproveitadas no trabalho (CHEN; BOZEMAN, } \\
\text { 2014). }\end{array}$ \\
\hline $\begin{array}{l}\text { Percepção de trabalho menos estimu- } \\
\text { lante (CHEN; BozEMAN, 2014). }\end{array}$ & $\begin{array}{l}\text { Percepção de que trabalho é estimulante } \\
\text { (CHEN; BOZEMAN, 2014). }\end{array}$ \\
\hline $\begin{array}{l}\text { Avaliação de serviços é mais complexa e } \\
\text { fins não são facilmente mensuráveis } \\
\text { (BAcon et al., 1996). }\end{array}$ & $\begin{array}{l}\text { Avaliação dos serviços é mais simples, na } \\
\text { medida em que o fim é o lucro da empresa } \\
\text { (BAcon et al., 1996). }\end{array}$ \\
\hline $\begin{array}{l}\text { Gestores devem coordenar atividades } \\
\text { que transpõem fronteiras de autoridade. }\end{array}$ & $\begin{array}{l}\text { Gestores se mantêm nas fronteiras de } \\
\text { autoridade. }\end{array}$ \\
\hline $\begin{array}{l}\text { Desafios da accountability, além do } \\
\text { controle por pares, por grupos de } \\
\text { interesse e órgãos de controle. Fontes } \\
\text { diversas de autoridade e legitimidade. }\end{array}$ & $\begin{array}{l}\text { Controle apenas pelos superiores e } \\
\text { acionistas da organização. Fontes claras } \\
\text { de autoridade e legitimidade. }\end{array}$ \\
\hline
\end{tabular}

Fonte: Elaboração própria.

público é mais complexa, uma vez que seus fins últimos não são tão facilmente mensuráveis quanto o lucro final em uma empresa privada. Em segundo lugar, os BMEs no setor público têm que coordenar atividades que transpõem múltiplas fronteiras de autoridade. No setor público, os desafios de accountability extrapolam os extratos superiores e acionistas das organizações privadas e incluem atores políticos, grupos de interesse e cidadãos, além de órgãos de controle. Assim, os BMEs no setor público lidam com um conjunto mais complexo de autoridade e fontes de legitimação.

As diferentes motivações dos servidores também são explicadas por dimensões institucionais ou organizacionais, que influenciariam ou condicionariam as percepções dos gestores por meio do processo seletivo dos gestores, que privilegiaria determinados perfis (MonTEIRO, 2013), pelo processo de treinamento e desenvolvimento de competências (OliveIRA et al., 2010), ou por incentivos e formas de gestão aplicadas pelas organizações (WISE, 2004).

Sistematizando os apontamentos da literatura levantados acima, podem ser identificadas como questões e conclusões centrais que a literatura tem abordado: a) valores e motivações dos servidores são relevantes para compreender sua forma de atuação e os resultados das políticas; b) isso é ainda mais relevante considerando-se a posição dos intermediários ou gestores, que podem influenciar 
seus subordinados; c) valores e motivações dos burocratas no serviço público são distintos das demais organizações e podem ser afetados por questões institucionais ou organizacionais; d) processos de reforma têm tentado alterar os valores e motivações dos gestores, mas nem sempre com sucesso.

\section{Perspectivas analíticas sobre a atuação dos burocratas de médio escalão}

A revisão empreendida permitiu identificarmos três principais perspectivas para o exame da atuação dos BMEs nas políticas públicas, abaixo descritas.

\section{a) Perspectiva estrutural}

A perspectiva estrutural concebe a atuação de burocratas como função do lugar que ocupa nas estruturas organizacionais e dos papéis definidos nos ordenamentos formais. Nesse sentido, os BMEs podem ser compreendidos como "engrenagens" de um mecanismo, tendo sua atuação predefinida por uma estrutura organizacional e normativa mais ampla (WISE, 2004).

Essa perspectiva é tributária da obra de Max Weber, o qual compreendia a burocracia como um sistema de dominação impessoal. Nesse sistema, os agentes de dominação não se confundem com (ou não tem propriedade sobre) os meios de administração, e suas condutas são orientadas pela obediência a regras formais (estatutos). Além disso, tais agentes estão inseridos em cadeias de comando hierárquico bem definidas, a partir das quais os superiores determinam o cumprimento de tarefas pelos subordinados. Assim, em tese, o comportamento de burocratas não dependeria das características, inclinações ou paixões dos agentes que habitam tais organizações, mas, sim, seria produto das normas e estruturas formais que definem as organizações nas quais atuam, derivando diretamente de uma "lógica da adequação" (MARCH; OLSEN, 1984), na qual os agentes identificam seu papel (a partir do lugar que ocupam na estrutura) e compreendem as obrigações e tarefas a ele associadas.

A perspectiva estrutural não oferece recursos analíticos que proporcionem uma compreensão particularizada da atuação dos BMEs. Tal como descrito, a atuação dos BMEs deveria ser compreendida como a de outros tipos de burocratas, a partir de sua inserção na estrutura organizacional, do cargo que ocupa e das normas que orientam o funcionamento de sua organização. Ademais, essa perspectiva pouco auxilia na compreensão das relações entre distintas burocracias e suas consequências para a produção de políticas públicas, já que a atuação burocrática é percebida de maneira estanque, predefinida pela posição ocupada e sua respectiva função na hierarquia organizacional. 


\section{b) Perspectiva de ação individual}

Um segundo enquadramento analítico para compreensão da atuação dos BMEs direciona o foco para suas decisões e ações individuais, a partir de cálculos racionais sobre as recompensas e expectativas de sanções. A abordagem da Escolha Pública (Public Choice) ofereceu algumas das primeiras formalizações de modelos focados no potencial de "agência" dos burocratas (Buchanan; Tullock, 1962). A premissa básica, diferentemente da perspectiva anterior, é de que a atuação de burocratas é motivada pela maximização de seus próprios interesses e ganhos pessoais. Niskanen (1971), um dos pioneiros nessa linha, propôs concebermos burocratas como agentes que buscam instrumentalmente a maximização dos orçamentos e recursos (financeiros e humanos) de suas organizações. Em seu modelo, esses atores se encontram em posição de assimetria de informação em relação aos Legislativos (assim como os dirigentes políticos do Executivo), pois, além de conhecerem as demandas externas, têm o monopólio das informações sobre os custos dos serviços que prestam. Assim, burocratas tenderão sempre a orientar seu comportamento para a ampliação crescente de seus orçamentos e recursos, ainda que extrapolem as necessidades efetivas da provisão de seus serviços ${ }^{4}$.

Essa perspectiva de interação racional-estratégica se tornou mais sofisticada a partir do modelo principal-agent (MoE, 1984), que introduz a ênfase sobre o papel dos incentivos e dos mecanismos de monitoramento nas relações entre burocratas, políticos e cidadãos. A atuação dos burocratas passa a ser compreendida como produto de decisões racionais que, por sua vez, decorrem de incentivos disponíveis e das expectativas de controle sobre o cumprimento de objetivos e metas propostas.

Portanto, a forma de compreender a atuação de burocratas nessa perspectiva se assemelha ao funcionamento dos mercados, marcados pela competição entre agentes que buscam seus interesses e estabelecem transações a partir dos incentivos e constrangimentos oferecidos.

O estudo de Breton e Wintrobe (1986) sobre o funcionamento da burocracia na Alemanha nazista oferece uma ilustração convincente desse tipo de argumento.

\footnotetext{
${ }^{4}$ A abordagem da Escolha Pública sobre o comportamento de burocratas foi amplamente criticada por restringir as motivações de tais agentes à maximização de seus interesses. Diversos autores contraargumentaram no sentido de uma visão mais complexa sobre motivações dos servidores públicos (ver WISE, 2004; ou a literatura sobre "public service motivation" - JACOBSON, 2011).
} 
Segundo os autores, a burocracia alemã era marcada por ordenamentos formais ambíguos, organizações com funções sobrepostas, linhas de autoridade pouco claras e ordens imprecisas, promovendo confusões entre jurisdições e duplicação de responsabilidades. O comportamento dos burocratas de médio escalão dificilmente poderia ser compreendido a partir das estruturas e normas formais do regime. No entanto, tal como argumentam os autores, a implementação efetiva da "solução final" para a "questão judaica" se deveu a uma dinâmica de competição interna entre dirigentes e burocratas de agências diversas, que buscavam, isoladamente, avançar o projeto de Hitler, na expectativa de reconhecimento e lealdade pessoal. Assim, os autores questionam a imagem tradicional de uma burocracia impessoal e hierárquica, na qual o comportamento dos burocratas é ditado por regras e ordens de superiores, propondo um modelo baseado em competição e trocas interessadas, envolvendo empreendedorismo e iniciativas voltadas para o avanço dos objetivos de seus líderes ou superiores hierárquicos ${ }^{5}$.

Diversos estudos sobre organizações do setor privado têm se dedicado a compreender justamente o empreendedorismo e a iniciativa criativa dos gerentes de nível intermediário, tal como demonstram Kelly e Gennard (2007) e Kuratko et al. (2005). Esses últimos afirmaram que o comportamento empreendedor dos BMEs se manifesta em um conjunto de atividades, como endosso, refinamento e cultivo de propostas de ação oriundas de seus superiores, além da identificação, aquisição e alocação dos recursos necessários para a realização dessas propostas. Em cada um desses momentos, os BMEs percebem oportunidades de interferência e redirecionamento dos processos em função de seus interesses e objetivos na organização.

Em suma, a perspectiva da ação individual permite um olhar para os BMEs que destaca seu poder de iniciativa e potencial de empreendedorismo, em contraponto ao papel passivo sugerido pela perspectiva estrutural. No entanto, ainda falha em compreender a inserção desses burocratas em redes sociais complexas.

\section{c) Perspectiva relacional}

Uma terceira perspectiva para compreender a atuação de burocratas enfatiza as relações que esses atores estabelecem com os demais atores do seu entorno.

\footnotetext{
${ }^{5}$ Apesar da natureza totalitária do regime nazista alemão ser um fator importante, especialmente a respeito da busca de lealdade pelos burocratas, argumentam que o padrão competitivo identificado se aplica a muitos outros casos de burocracias nos setores público e privado.
} 
Essa perspectiva surgiu nos anos mais recentes, a partir de modelos que buscam compreender o Estado e as políticas públicas numa ótica mais abrangente, considerando que as políticas são marcadas por múltiplas redes de atores internos e externos ao Estado capazes de alterar o desenho e os resultados das políticas. Essas novas abordagens, ancoradas nas ideias de governança e de redes sociais, buscam compreender o funcionamento das organizações estatais, considerando não a estrutura formal ou a atuação individual dos agentes, mas, sim, como essas são condicionadas e alteradas pelas múltiplas interações com agentes estatais, privados ou sociais que, por meio das relações sociais, influenciam o Estado.

Essa abordagem também está presente na análise que alguns autores fazem sobre a atuação dos BMEs. As questões que norteiam as pesquisas buscam compreender, por exemplo, como esses burocratas interagem com uma rede de atores internos e externos ao Estado; como influenciam e regulam as relações dos próprios implementadores; como mediam e mobilizam as relações entre implementação e formulação etc. Consideram, por fim, que esses burocratas são um elo fundamental entre as regras e sua aplicação prática, entre o mundo da política e o implementador que se relaciona com o usuário, entre as múltiplas agências e seus entendimentos para construção de consensos em torno das políticas públicas.

Nessa perspectiva, os BMEs foram interpretados como atores que interativamente sintetizam e disseminam informações para os níveis superiores e inferiores da organização. Assim, ganham relevância as responsabilidades cognitivas e comunicacionais desses atores que, dada sua posição estrutural, estão sempre em interação, agindo entre outros atores a seu redor, reconciliando as distintas perspectivas do topo e da base (além do entorno). Para Kuratko et al. (2005), essas características diferenciam os BMEs de outros atores burocráticos e os situam em posição privilegiada para a promoção de inovações.

Uma das formas de se exercitar uma perspectiva relacional sobre os BMEs envolve percebê-los como parte de grupos, coalizões ou facções que compartilham crenças, valores e propostas e que estabelecem disputas com outros grupos no interior de ou entre organizações. Assim, suas decisões e comportamentos só podem ser compreendidos a partir de sua inserção em dinâmicas coletivas ou interativas, ou seja, sua relação com outros atores envolvidos na política. Narayanan e Fahey (1982) propuseram analisar esses processos a partir de um modelo de coalizações temáticas, isto é, por meio da inserção de burocratas em coalizões e das disputas entre elas. Segundo os autores, as influências dessas disputas se manifestam tanto no nível substantivo quanto no simbólico.

Analisando o trabalho em cinco diferentes clínicas, Heimer (2013) aponta que, em políticas que são implementadas por múltiplas agências (o que o autor 
denomina de processos regulatórios), as organizações precisam ser capazes de representar todos os lados - tanto demandantes das políticas, como reguladores delas. Nesses contextos, os burocratas têm um papel fundamental de transmitirem informações para cima e para baixo na cadeia regulatória, além de traduzirem entre o local e o universal e facilitarem ajustes para o entendimento correto do papel de cada uma das organizações envolvidas no processo. Nesse processo, estabelecem-se constantes práticas de tradução, readaptação, recategorização das normas para inseri-las no contexto local. Assim, essas organizações funcionam como meio da cadeia e/ou nós regulatórios, ensinando aos subordinados a cooperarem com os reguladores e vice-versa, e quem desempenha esse papel de possibilitar a atuação das organizações são os burocratas intermediários.

Nessa mesma lógica, Huising e Silbey (2011) consideram que os burocratas de médio escalão são os atores responsáveis por interagir com seus subordinados e garantir deles complacência para implementação das regras desenhadas por níveis superiores. Para as autoras, o papel desses gestores é de governar o gap existente entre as regras e a possibilidade real de aplicação, o que chamam de regular as relações. Para tanto, gestores exercem diferentes tipos de práticas de governança de gap, que passam por narração das expectativas existentes, questionamento das regras e práticas, síntese do que aprendem e elaboração de acomodações pragmáticas que permitam adaptar as regras gerais aos contextos locais. No entanto, consideram que, para uma atuação de sucesso dos BMEs, são necessárias condições, como a existência de um ator externo que cobre resultados e transparência, e a garantia de flexibilidade e liberdade para adaptação das regras - portanto, discricionariedade.

A partir de um survey aplicado a implementadores de um programa social americano, Keiser (2010) chega a conclusão semelhante, afirmando que o papel central dos BMEs é de interagirem com os burocratas implementadores e com outras agências para regular a interação entre esses vários atores e direcionar a forma de implementação, construindo consensos a respeito de valores compartilhados.

Há nessas perspectivas uma ideia central de que o posicionamento intermediário dos burocratas de médio escalão confere-lhes a capacidade de criar e regular as relações entre as diversas agências paralelas ou entre as instâncias superiores e inferiores da hierarquia organizacional. Esse papel faz com que esse burocrata assuma posições estratégicas, não apenas por regular como as relações se darão, mas também por ser centralizador de informações.

Alexander et al. (2011) chegam a semelhante conclusão analisando as redes sociais de conselhos e informações estratégicas de 765 atores, entre eles 
burocratas de médio e alto escalão, e de políticos em 11 municípios australianos. Objetivando compreender com quem os diversos segmentos do Estado contatavam para conseguirem conselhos ou informações estratégicas, os autores concluem que os BMEs são a maior fonte desse tipo de informações, tanto para políticos, como para o alto escalão da burocracia. Além disso, a pesquisa também demonstra que os próprios BMEs procuram outros burocratas de médio escalão para conseguirem informações e conselhos - gerando homofilia em suas interações ${ }^{6}$. Embora concluam afirmando que os resultados das pesquisas variam entre municípios (o que demonstra que há aspectos contextuais nas configurações relacionais), os autores demonstram a posição estratégica que os BMEs assumem e como, portanto, se tornam importantes para o funcionamento das organizações públicas.

\section{Quadro 2: Principais autores de cada perspectiva}

\begin{tabular}{|l|l|l|}
\hline Perspectiva estrutural & Perspectiva ação individual & Perspectiva relacional \\
\hline Weber (1981) & Buchanan e Tollock (1962) & Kuratko et al. (2005) \\
Wise (2004) & Niskanen (1971) & Narayanan e Fahey (1982) \\
& Moe (1984) & Heimer (2013) \\
& Breton e Wintrobe (1986) & Huising e Silbey (2011) \\
& Kelly e Gennard (2007) & Keiser (2010) \\
& Kuratko et al. (2005) & Alexander et al. (2011) \\
& & Vakkuri (2010) \\
& & Johansson (2012) \\
\hline
\end{tabular}

Fonte: Elaboração própria.

Vale ressaltar que, para essa perspectiva, os BMEs não apenas intermedeiam as relações, mas realizam práticas que permitem que elas sejam adaptadas e traduzidas aos diversos contextos da interação, tal como apontado por Vakkuri (2010).

Nesse sentido, Johansson (2012), analisando gestores de infraestrutura, conclui que há certos tipos de agentes envolvidos com a implementação que atuam como gestores de negociação, especialmente quando há políticas fragmentadas e que envolvem múltiplos stakeholders. Nesse caso, os gestores desenvolvem métodos de negociação que permitem às políticas alcançarem efetividade, e essas

\footnotetext{
${ }^{6}$ Conceito utilizado pela análise de redes sociais, que considera relações entre pessoas com perfis e características individuais semelhantes.
} 
negociações dependem de discricionariedade. Certas posições, afirma o autor, requerem que os burocratas se tornem negociadores entre stakeholders, e é sua capacidade de negociação com as diferentes agências e interesses que permite à política ter resultados.

Com a descrição das três perspectivas analíticas sobre a atuação dos BMEs, torna-se inevitável a percepção de suas correspondências com os três princípios organizacionais - hierarquia, mercado e redes - que têm marcado os debates sobre governança e teorias do Estado. Isso sugere que a análise da atuação dos BMEs se insere em movimentos maiores de análise da própria atuação do Estado e de grandes organizações. Da mesma forma que a organização e operação do Estado se complexifica, partindo de um padrão marcado pela predominância de arranjos hierárquicos para padrões mesclados com os princípios do mercado e das redes, mais sofisticadas precisam ser as perspectivas analíticas para interpretação da atuação de atores burocráticos. Conforme se percebe ao longo desta revisão da literatura, as abordagens analíticas mais recentes têm procurado introduzir um componente relacional-interativo às perspectivas anteriores, limitadas às reflexões a partir de estruturas ou da ação individual.

\section{Os burocratas de médio escalão em ação: análises setoriais}

A partir da definição de quem são, onde atuam e quais os olhares teóricos existentes acerca dos burocratas de médio escalão, analisamos alguns trabalhos sobre a sua atuação em contextos específicos de políticas públicas. A análise a partir de enfoques setoriais é bastante parca na literatura sobre burocracia de médio escalão encontrada. Assim, para além de compreender como as análises setoriais se utilizam das discussões teóricas apresentadas, apropriando-se (ou não) das mesmas, intentamos observar como o BME é percebido nos distintos contextos organizacionais, a partir da premissa de que não apenas diferentes posições hierárquicas produzem distintas possibilidades de atuação, mas também de que distintos campos produzem lógicas e culturas organizacionais variadas, impactando a atuação desses burocratas, conforme apontaram Oliveira e Abrucio (2011). Ou seja, o enfoque aqui não é dar conta de todas as análises setoriais, nem esgotar essa literatura, visto, inclusive, que ela é bastante incipiente, mas trazer à luz algumas possibilidades de análises baseadas em setores específicos e suas contribuições para a discussão.

Quanto às áreas de políticas públicas, muitos dos trabalhos setoriais encontrados lidam com a política de educação e ambiente escolar, analisando o papel dos diretores como BMEs que fazem a interlocução com os burocratas implementadores, que são aqueles que interagem diretamente com a população (chamados na 
literatura por burocratas de nível de rua). A diferenciação fundamental entre esses diretores e os burocratas de nível de rua está na responsabilidade, dos primeiros, de gerenciar equipes definindo a forma como os burocratas que interagem com usuários vão agir. Esse papel dos diretores se reforça ainda mais a partir dos processos de descentralização das políticas sociais vivenciados por vários países nas últimas décadas, que tiveram como consequência a autonomização de uma série de serviços públicos. Esse processo, observado no caso canadense, transformou as escolas públicas em "unidade de prestação de contas" (CATTONAR, 2006), sendo responsável localmente pelo bom desempenho dos alunos.

Mais do que zelar pelo bom desempenho dos alunos, Cattonar (2006) lembranos, citando Pelage (1998), que, na França, o diretor de escola, enquanto "chefe do estabelecimento", deve combinar competências variadas: "rigor administrativo e mobilização dos recursos humanos, eficiência gerencial e compromisso com os resultados, responsabilidades e inovação pedagógica" (CATtonaR, 2006, p. 188).

Nesse contexto, um problema percebido como relevante para o cotidiano dos BMEs foi a competição entre as escolas, sobretudo a partir dos índices padronizados para todo o país, com aplicação de exames nacionais. Da mesma maneira, também na Inglaterra, os diretores passaram a ser percebidos como "agentes de mudança" do ambiente escolar, o que difere sobremaneira da realidade dos anos 1980, quando eram percebidos "como membros do pessoal docente cuja função principal era dirigir os outros docentes" (op.cit., p.188).

Mas, salienta Cattonar, há grandes variações quando observados os diferentes governos regionais canadenses: enquanto algumas províncias estão mais voltadas para a política de resultados, outras estão mais atentas à necessidade de ampliação da participação dos pais na gestão das escolas. Mais do que isso, a pesquisa mostra que a percepção dos diretores, no que se refere ao (novo) papel da escola, difere, também, “(...) de acordo com outras variáveis contextuais, como o nível de ensino, o perfil da clientela escolar e a localização urbana ou rural da escola que dirigem" (Cattonar, 2006, p. 194).

Assim, a atuação dos BMEs é influenciada não apenas pelo seu perfil, relacionado à sua formação profissional e história de vida, mas também pelo contexto no qual atua e pelas interações em que se encontra envolvido, tal como proposto pela perspectiva relacional de análise da burocracia.

No caso brasileiro, o mesmo foi percebido por Santana et al. (2012). Por meio de um questionário aplicado a 327 diretores de 52 municípios de Minas Gerais, os autores analisaram o nível de satisfação no trabalho e a qualidade de vida no trabalho, medidos por meio de variáveis relacionadas à percepção quanto à compensação, se justa e adequada; condições de saúde e segurança no trabalho; 
equilíbrio entre trabalho e vida pessoal; entre outros. Eles demonstraram que as diferentes regionais de ensino apresentam níveis distintos de satisfação dos diretores quanto à sua atuação profissional, o que significa que o ambiente no qual os diretores atuam importa não apenas para o resultado obtido pela escola, mas também para o nível de satisfação da equipe com o trabalho.

Outro aspecto apontado pelos estudos sobre diretores de escola diz respeito à percepção de que esses burocratas realizam tarefas múltiplas, envolvendo administração pedagógica, prestação de contas, supervisão de professores, gestão da ordem interna, gestão de recursos e gestão de relações externas.

O perfil "multifunção" dos burocratas de médio escalão atuantes no ambiente escolar corrobora um dos aspectos salientados por Currie e Procter (2003) no que diz respeito a outra BME específica, que é aquela da área da saúde. Observando três diferentes hospitais públicos do Reino Unido, os autores demonstram que uma das características verificadas nos BMEs é sua capacidade de lidar com distintas responsabilidades, por um lado, e liderar equipes multidisciplinares, por outro. Assim, diretores hospitalares (no caso, diretores de especialidades clínicas), tal como diretores de escolas, lidam com burocracias de nível de rua de distintas áreas e atuações - enfermeiros, técnicos de laboratório, nutricionistas etc., no caso dos hospitais; professores, técnicos administrativos, cozinheiros etc., no caso das escolas.

A capacidade de assumir distintas tarefas e responsabilidades, gerenciando profissionais de diferentes áreas, só é possível em função de outra característica da BME descrita por Currie e Procter (2003), que é o domínio sobre a dinâmica dos serviços que gerenciam em função de um conhecimento técnico indispensável para a liderança, somado a uma capacidade de diálogo com os níveis superiores da estrutura institucional burocrática, o que envolve, inclusive, uma habilidade política, tal como salientado por Yesilkagit e Thiel (2008).

Dessa maneira, Pereira e Silva (2011), observando os gestores de três instituições federais de educação superior (IFES) brasileiras, mencionam que há quatro distintas competências gerenciais requeridas: cognitivas, funcionais, comportamentais e políticas. No entanto, nem sempre as competências exigidas oficialmente para a seleção dos BMEs são aquelas de fato percebidas pelos burocratas como essenciais para a execução de suas tarefas diárias. Esse distanciamento foi percebido por Silva (2011), ao analisar a construção da identidade dos diretores de escola sob dois enfoques: à luz do discurso oficial e por meio dos discursos dos diretores.

Ao analisar os diretores clínicos dos hospitais, os autores apontam um fator importante para a compreensão do que pode influenciar a atuação dessa 
burocracia: algumas corporações mais coesas, como a dos médicos, influenciam sobremaneira a BME ao impor seus próprios objetivos e percepções. Assim, no caso dos diretores hospitalares, não apenas gerenciam médicos como são, eles próprios, parte da categoria.

Portanto, apontam para um aspecto importante, sobretudo quando salientamos as diferenças entre áreas de políticas públicas, que é o fato de que algumas categorias têm maior poder para se opor aos comandos da BME do que outras, quando não é de seu interesse. Além disso, quando há convergência entre a categoria da BME e aquela sob seu comando, sendo essa "poderosamente autônoma", mais difícil será a implementação de políticas e diretrizes do alto escalão que sejam por eles vistas como contrárias aos seus interesses ou percepções acerca de qual deve ser a sua atuação.

No entanto, também lembram que a própria BME pode, independentemente da vontade da burocracia sob seu comando, não seguir os comandos dos seus superiores hierárquicos, como salientado pelo modelo de Floyd e Wooldridge (1992).

Nesse sentido, enfatizam que muita autonomia para a BME pode ser deletéria. No caso dos hospitais (assim como boa parte dos serviços públicos), algum grau de autonomia é importante para possibilitar adaptações locais, mas muita autonomia da BME pode gerar grande variação nos resultados alcançados por serviços públicos similares, conforme demonstraram Oliveira e Abrucio (2011) ao analisarem os hospitais públicos do estado de São Paulo. Ademais, com a centralização decisória de uma série de políticas públicas, processo esse que vem ocorrendo em várias democracias que haviam promovido, nos anos 1980 e 1990, intensa descentralização, acaba-se gerando regulamentações governamentais e controles sobre as políticas públicas para garantir o alcance de metas e padrões de eficiência que demandam a diminuição da autonomia da burocracia atuante no nível local (CURrie; Procter, 2003, p. 1340).

Enfim, o que os trabalhos das diferentes áreas de políticas públicas demonstraram foi que as características definidoras dessa burocracia, embora presentes nos distintos setores de atuação, são também influenciadas pelo contexto no qual as organizações agem, por um lado, e pelas lógicas internas de cada área de política pública e categorias profissionais que nelas atuam, por outro.

\section{Considerações finais}

Definidos como aqueles que interagem tanto com o alto escalão quanto com a burocracia implementadora, detentores de conhecimento técnico para a liderança dessa, bem como de habilidade de diálogo técnico e político com a burocracia 
formuladora, os burocratas de médio escalão são, portanto, peças-chave do complexo emaranhado de interações que envolvem a implementação de políticas públicas. Isto é, o foco na atuação desses agentes e nas relações que se estabelecem a partir deles expande nossas capacidades de compreender os processos de produção de políticas públicas.

Apresentar essa perspectiva foi o principal objetivo do presente artigo, o qual buscou sistematizar e destacar diferentes olhares promovidos pela literatura especializada para se refletir sobre os burocratas de médio escalão. Três dimensões da atuação desses atores foram analisadas: (a) seus papéis, funções e "lugares"; (b) as perspectivas analíticas a partir das quais são observados; e (c) a sua atuação nas políticas públicas setoriais. Em cada uma dessas dimensões, buscou-se retratar a diversidade de abordagens e tratamentos ao burocrata de médio escalão e sua atuação e influência sobre os processos de produção de políticas, como, por exemplo, em comparações entre os setores público e privado e entre distintas áreas de atuação do Estado.

Dois aspectos merecem destaque a partir da revisão bibliográfica aqui empreendida. Em primeiro lugar, percebeu-se que, da mesma forma que a organização e a operação do Estado têm se complexificado ao longo do tempo partindo de um padrão marcado pela predominância de arranjos hierárquicos para padrões mesclados com os princípios do mercado e das redes -, mais sofisticadas precisam ser as perspectivas analíticas para interpretação da atuação de atores burocráticos. A revisão da literatura demonstra que as abordagens analíticas mais recentes têm procurado introduzir um componente relacionalinterativo às perspectivas anteriores (estrutural e individual-competitiva).

Em segundo lugar, explicitam-se as ausências existentes na literatura nacional, no que tange à relevância e centralidade desse ator. Como indicado ao longo do texto, maior atenção aos BMEs nas análises dos processos de produção de políticas públicas oferece ganhos analíticos e interpretativos importantes. Compreender a atuação dessa burocracia específica nos diferentes contextos e áreas de políticas públicas, sua relação "para cima" e "para baixo" e os efeitos dessa atuação para a implementação (e reformulação) das políticas são os desafios que a literatura brasileira do campo de políticas públicas terá que enfrentar, com vistas a compreender de maneira mais ampla a complexa rede de relacionamentos e interações que envolvem esses processos. 


\section{Referências bibliográficas}

Aberbach, J. D.; Rockman, B. A. Bureaucrats and Politicians: a report on the administrative elites Project. Australian Journal of Public Administration, v. 50, p. 203-217, 1991.

Alexander, D.; Lewis, J. M.; Considine, M. How Politicians and Bureaucrats Network: a comparison across governments". Public Administration, v. 89, p. 1274-1292, 2011. Bacon, K.; Bunch, R.; Cameron, C. D.; Deis, R.; Morgan, D. What middle managers do in local government: stewardship of the public trust and the limits of reinventing government", Public Administration Review, v.56, no 4 (July-August), p.359-366, 1996.

BIANCCHI, T. Redistribution within a democratic society: the "finished business" of the Italian agrarian reform. 2002. Dissertação (Ph.D) - Department of Urban Studies and Planning, Massachusetts Institute of Technology, 2002.

Breton, A.; Wintrobe, Ronald. The Bureaucracy of Murder Revisited, Journal of Political Economy, v. 94, no 5, p.905-926, (Oct.)1986.

Buchanan, J. M.; Gordon, T. The Calculus of Consent. Ann Arbor: University of Michigan Press, 1962.

CATtonar, B. Evolução do modo de regulação escolar e reestruturação da função de diretor de escola. Educação em Revista, Belo Horizonte, v. 44, 2006.

Chareanpunsirikula, S.; Wood, R. C. Mintzberg, managers and methodology: some observations from a study of hotel general managers. Tourism Management, $\mathrm{n}$ 23, p.551-556, 2002.

Chen, C.-A.; Bozeman, B. Am I a Public Servant or Am I a Pathogen? Public Managers' Sector Comparison of Worker Abilities". Public Administration, 2014.

Cooper, C; KNotTs, G., et al. Taking Personality Seriously

The Five-Factor Model and Public Management. American Review of Public Administration, v. 43, p. 397-415, 2012.

CurRIE, G.; Procter, S. The Antecedents of Middle Managers' Strategic Contribution: The Case of a Professional. Journal of Management Studies, v. 42, no 7, p.99-117, November 2005.

Dalton, M. Men who manage. New York: John Wiley \& Sons, 1959.

DemiR, T.; Reddick, C. Understanding Shared Roles in Policy and Administration: An Empirical Study of Council-Manager Relations. Public Administration Review v. 72, no 4, p. 526-535, July/August 2012.

Falavigna, G.; Ippolitti, R.; Manello, A. Hospital organization and performance: a directional distance function approach. Health Care Management Science, v. 16, p. 139-151, 2013.

FariA, Carlos Aurélio Pimenta. Idéias, Conhecimento e Políticas Públicas: Um Inventário Sucinto das Principais Vertentes Analíticas Recentes. Revista Brasileira de Ciências Sociais, v. 18, no 51, p. 21-30, 2003. 
FloYd, S. W.; WooldRIDGe, B. Middle Management Involvement in Strategy and its Association with Strategic Type: A Research Note. Strategic Management Journal, 1992.

GaIns, F.; John, P. What Do Bureaucrats Like Doing? Bureaucratic Preferences in Response to Institutional Reform. Public Administration Review, v. 70, p. 455-463, 2010.

Hallet, T. The Myth Incarnate: Recoupling Processes, Turmoil, and Inhabited Institutions in an Urban Elementary School. American Sociological Review vol. 75, no 1, p.52-74, February 2010.

Hallett, T., Ventresca, M. Inhabited Institutions: Social Interactions and Organizational Forms in Gouldner's Patterns of Industrial Bureaucracy. Theory and Society. v. 35, no 2, p. 213-236, v2006.

Heimer, C. Resilience in the middle. Annals of American Academy of Political and Social Science. v. 649, № 1, p. 139-156, September 2013.

HowletT, M. Public Managers as the Missing Variable in Policy Studies: An Empirical Investigation Using Canadian Data. Review of Policy Research, v. 28, no 3, p. 247263, May 2011.

HuIsIng, R.; SILBEY, S. S. Governing the gap: Forging safe science through relational regulation. Regulation \& Governance, v. 5, p. 14-42, 2011.

JaCoBSEN, D. I. Local Authority Bureaucracies: Responsible, Representative, or Divergent? Evidence from small political systems in Norway. Public Administration, v. 90, p. 1067-1087, 2012.

JACOBSON, W. S. Creating a motivated workforce: how organizations can enhance and develop public service motivation (PSM). Public Personnel Management, no 40, v. 3 (Fall), p. 215, 2011.

Johansson, V. Negotiating Bureaucrats. Public Administration, v. 90, no 4, p. 1032 1046, December 2012.

Kanashiro, F.; MeneghettI, J. Burocracia como organização, poder e controle. Revista de Administração de Empresas, v. 51, no 5, set-out 2011.

KAUFMAN, H. The forest ranger: a study in administrative behavior. Baltimore: Johns Hopkins Press, 1960.

KEISER, L. Understanding Street-Level Bureaucrats' Decision Making: Determining Eligibility in the Social Security Disability Program. Public Administration Review, v. 70, no 2, p. 247-257, March/April 2010.

Kelly, J.; Gennard, J. Business strategic decision making: the role and influence of directors. Human Resource Management Journal, v. 17, № 2, p.99-117, 2007.

KHALL, D; KIM, J. Contracts Offered by Bureaucrats. RAND Journal of Economics, v. 44, no 4, Winter p. 686-711, 2013.

Klein, P. G., Mahoney, J. T., Mcgahan, A. M.; Pitelis, C. N. Capabilities and Strategic Entrepreneurship in Public Organizations Strat. Entrepreneurship Journal, v. 7, p. 70-91, 2013. 
Kuratko, D.; Ireland, R. D.; Covin, J.; Hornsby, J. A model of middle-level managers' entrepreneurial behavior. Enterpreneurship Theory \& Practice, p.699-716, November 2005.

LEE, Y; WILINS, V. More similarities or more differences? Comparing Public and Nonprofit Managers' Job Motivations. Public Administration Review, v. 71, no 1, p. 45-56, January/February 2011.

LEWIS, G. B. Men and women toward the top: backgrounds, careers, and potential of federal middle managers. Public Personnel Management, v. 21, no 4 (Winter), p. 473, 1992.

LotTA, G. LotTA, G. S. Implementação de políticas públicas: o impacto dos fatores relacionais e organizacionais sobre a atuação dos burocratas de nível de rua no Programa Saúde da Família. 2010. Tese (Doutorado) - Universidade de São Paulo, Departamento de Ciência Política, São Paulo.

MARCH, J. G.; Olsen, J. P. Rediscovering Institutions. Toronto: Free Press, 1989.

McGURK, P. The realities of management and leadership development for public managers. International Journal of Public Sector Management, v. 22, no 6, p.464 477, 2009.

Meyer, R.; Egger-Peitler, I; Höllerer, M; Hammerschmid, G. Of bureaucrats and passionate public managers: Institutional logics, executive identities, and public service motivation. Public Administration, 2013.

MintzBeRG, H. The nature of managerial work. New York: Harper \& Row, 1973.

MoE, T. The New Economics of Organization. American Journal of political Science, v. 28, p.39-777, 1984.

MontelRo, L. Reforma da administração pública e carreiras de Estado: o caso dos especialistas em políticas públicas e gestão governamental no Poder Executivo federal. Revista de Administração Pública, v. 47, № 5, 2013.

Narayanan, V.K.; Fahey, L. The Micro-Politics of Strategy Formulation. Academy of Management Review, v. 7, no I., p.25-34, 1982.

Niskanen, W. A. Bureaucracy and Representative Government. Chicago: Aldine Atherton, 1971.

Oliveira, F., SAnt'AnNa, A; VAz, S. Liderança no contexto da nova administração pública: uma análise sob a perspectiva de gestores públicos de Minas Gerais e Rio de Janeiro. Revista de Administração Pública, Rio de Janeiro, v. 44, no 6, Nov./Dec. 2010. OliveiRA, V. E. Instituições, burocracia e produção de políticas públicas: o caso da política estadual de saúde. Artigo apresentado no 33 ENCONTRO ANUAL DA ANPOCS, Caxambu, MG, 2009.

Oliveira, V. E.; Abrucio, F. L. Entre a política e a burocracia: a importância dos burocratas de nível médio para a produção de políticas públicas em saúde e educação. Artigo apresentado no 35 ENCONTRO ANUAL DA ANPOCS, Caxambu, MG, 2011. 
Parka, S; Raineyb, H. Work motivation and social communication among public managers". The International Journal of Human Resource Management, v. 23, v. 13, 2012.

Pereira, A. L. C.; Silva, A. B. As competências gerenciais nas instituições federais de educação superior. Cadernos EBAPE, v. 9, 2011.

PIRES, R. Burocracias, gerentes e suas "histórias de implementação": narrativas do sucesso e fracasso de programas federais. In: FARIA, C. A. P. (Org.). Implementação de Políticas Públicas: teoria e prática. Belo Horizonte: Editora PUC Minas, 2012. p.182-220, 2012.

Ponomariov, B. L.; Boardman, P. C. Organizational Pathology Compared to What? Impacts of Job Characteristics and Career Trajectory on Perceptions of Organizational Red Tape. Public Administration Review, v. 71, p. 582-597, 2011.

RocHA, C. V. Anatomia de uma reforma: descentralização da educação pública de Minas Gerais e mudança institucional. Dados: Revista de Ciências Sociais, v. 46, n. 3, p. 557-592, 2003.

Sabharwal, M. From Glass Ceiling to Glass Cliff: Women in Senior Executive Service. Journal of Public Administration, Research \& Theory, June 2013.

SANTANA, L. L. S. et al. Gestores escolares da rede públicas em MG: fatores de satisfação no trabalho. Educação em Revista, v. 28, n. 1, 2012.

SCHNeIDER, B. R. Burocracia pública e política industrial no Brasil. São Paulo: Sumaré, 1994.

SILVA, J.M.A. A Construção de Identidade de Diretores: discurso oficial e prática. Educação em Revista, v. 27, n. 3, 2011.

SOFER, C. Post Bureaucratic Organizations and Managers. OMEGA, The International Journal of Management Science, v. 2, no 3, p.313-334, 1974.

Thiel, S.; Steijn, B.; Aluix, M. New Public Managers in Europe' changes and trends. Artigo apresentado no IX Encontro da Sociedade Internacional de Pesquisa em Gestão Pública (IRSPM), Milão, 5-8 de abril de 2005.

Thomas, R.; LinsteAD, A. Losing the Plot? Middle Managers and Identity. Organization, v. 9, no 1, p.71-93, 2002.

VAKKURI, J. Struggling with ambiguity: Public Managers as User of NPM-Oriented Management Instruments. Public Administration, v. 88, no 4, p. 999-1024, December 2010.

VIE, O. E. Have post-bureaucratic changes occurred in managerial work?. European Management Journal, no 28, p.182-194, 2010.

Weber, M. Ensaios de Sociologia. Ed. Guanabara: Rio de Janeiro, 1981.

WILSON, J. Q. Varieties of police behavior: the management of law and order in eight communities. Cambridge: Harvard University Press, 1968.

WISE, L. R. Bureaucratic Posture: On the Need for a Composite Theory of Bureaucratic Behavior. Public Administration Review, v. 64, no 6, p.669-680, November/December 2004. 
Witesman, E.; Walters, L. Public Service Values: a new approach to the study of motivation in the public sphere. Public Administration, 2013.

Wu Xun; M. Ramesh; M. Howlett; SCOtT Fritzen. The public policy primer: managing the policy process. ROUTLEDGE, 2010.

Yesilkagit, K.; Thiel, S. Political Influence and Bureaucratic Autonomy. Public Organization Review, no 8, p.137-153, 2008.

Gabriela Spanghero Lotta

Pós-Doutoranda na Fundação Getúlio Vargas (FGV-SP), Doutora em Ciência Política pela Universidade de São Paulo (USP), Professora-Adjunta e Coordenadora do bacharelado em Políticas Públicas e da pós-graduação em Políticas Públicas da Universidade Federal do ABC (UFABC). Contato: gabriela.lotta@gmail.com

Roberto Rocha Coelho Pires

Doutor em Políticas Públicas pelo Massachusetts Institute of Technology (MIT), Técnico de Pesquisa e Planejamento do Instituto de Pesquisa Econômica Aplicada (Ipea), com atuação na Diretoria de Estudos do Estado, das Instituições e da Democracia (Diest). Contato: roberto.pires@ipea.gov.br

Vanessa Elias Oliveira

Doutora em Ciência Política pela Universidade de São Paulo, com período de doutorado-sanduíche na Columbia University. É Professora-Adjunta do bacharelado em Políticas Públicas e da pós-graduação em Políticas Públicas da Universidade Federal do ABC (UFABC). Contato: vanessa.oliveira@ufabc.edu.br 